\title{
Teachers' Experiences and Impact of Workplace Bullying on Their Health in Lesotho
}

\author{
Malineo Agnes Matsela \\ National University of Lesotho, \\ P O Roma, Lesotho
}

\author{
Tiaan (GJC) Kirsten \\ North West University (Potchefstroom Campus), \\ Potchefstroom, Republic of South Afria
}

\begin{abstract}
This article focuses on teachers' experiences and sources of workplace bullying as well as its impact on the health of teachers in Lesotho. Data from the interviews indicated that workplace bullying against teachers is highly prevalent. It further emerged that the workplace bullying they experienced had a serious impact on their health in all contexts of their existence namely biological, psychological, spiritual, ecological and metaphysical contexts that can be regarded as worktrauma. The sources of workplace bullying experienced by teachers are the management of schools to a large extent, followed by colleagues of equal status and parents, community and the students to a lesser extent. In the light of the findings the study recommends that, teacher support programmes should be put in place in order to address issues of workplace bullying and its impact on teachers' health.
\end{abstract}

Keywords: violence, workplace bullying, mobbing, work trauma, health promotion, teachers, Lesotho

\section{Introduction and Background of the Study}

The study of workplace bullying emerged in the 1990s and it is still gaining further recognition internationally (Rayner \& Keashly, 2005, p. 271; Notelaers, Einarsen, De Witte, \& Vermunt, 2006, p. 3). Studies in this area started in clinical work with severely traumatized individuals by Heinz Leymann, a German psychiatrist. He established the first trauma clinic in the 1980s. Furthermore, he also reported on the trauma that occurs as a result of persistent psychological terrorization that occurs in the workplace. He estimated that $11 \%$ of the country's suicides at the time, emanated from work related terrorization. Nevertheless, Andrea Adams who is viewed as the pioneer in the research on workplace bullying gave the new term "bullying" to the same phenomenon. The seriousness of the nature of this phenomenon became evident to the public in the way she exposed it in the newspapers and other media (Lewis, 1999).

Although research on workplace bullying is advancing there are various views given in the literature. Different researchers describe it in terms of their research and cultural orientations which actually determines how the phenomena is recognized and explained (Rayner, Sheehan, \& Barker, 1999, p. 2; G. D. Namie \& R. Namie, 2000, p. 3; Randall, 2001, p. 9; Gilioli \& Fingerht, 2003, p. 11; Omari, 2003, p. 8; Sheehan, Barker, $\&$ Mccarthy, 2004). This is observed from the various definitions given in the subsequent paragraphs.

According to G. D. Namie and R. Namie (2000, p. 1), workplace bullying is also viewed as "repeated,

Malineo Agnes Matsela, Ph.D., psychologist, Faculty of Education, National University of Lesotho.

Tiaan (GJC) Kirsten, Ph.D., senior lecturer, psychologist, School of Education, North West University (Potchefstroom Campus) RSA. 
malicious verbal treatment of a target by aharassing bully that is motivated by the wish to control the targeted individual". The latter researchers further argue that this control is a combination of intentional humiliation and embarrassment of the target or interference with his or her work and withholding of resources and support with an objective of preventing the targeted individual from succeeding at work.

According to Einarsen, Hoel, Zapf, and Cooper (2003, p. 15), workplace bullying means: harassing, offending, socially excluding someone or negatively affecting someone's work tasks. In order to be workplace bullying, the activity has to occur regularly. Again, Einarsen, Raknes, and Matthiesen (1994, p. 384) expounded on the definition of workplace bullying and described it as a situation where one or more persons persistently, over a certain period of time, perceive themselves to be on the receiving end of negative actions from one or several people in their workplace. This is aggravated by the fact that the victim has difficulties defending himself or herself against such actions.

This definition is given around the parameters of frequency, longevity, reaction to the behaviours, and power differences even though different authors try to emphasize different aspects of it (Rayner et al., 1999, p. 3 ). This definition shifts the focus to power imbalances throughout the organization instead of only the individual victims and perpetrators (Lewis \& Orford, 2005, p. 44).

From the foregoing exposition of various conceptualizations of workplace bullying, it shows that this phenomenon is not a minor misunderstanding and conflicts that occur daily. However, when such conflicts get out of control, a worker may find himself/herself in a prejudicial position where he or she ends up as a subject of stigmatization by his/her colleagues and management (Einarsen, Raknes, \& Matthiesen, 1994, p. 2). It is, therefore, concluded from these various literature sources that workplace bullying is a highly dynamic process and therefore the presence of negative behaviours should be seen as the necessary part of the problem but not a sufficient feature to explain the phenomenon as a whole (Rayner et al., 1999, p. 2; G. D. Namie \& R. Namie, 2000, p. 3; Tehrani, 2001, p. 5; Randall, 2001, p. 9; Einarsen et al., 2003, p. 2).

Despite numerous scholarly debates, it is clearly apparent from the literature that workplace bullying occurring in the workplace is a serious problem (Jackson \& Ashley, 2005).

In order to elucidate the various conceptualization of workplace bullying in the research literature, Rayner and Keashly (2005, p. 273) state that various definitions of workplace bullying in the work place contain the following main elements:

(1) The experience of negative behaviours;

(2) Behaviours that are experienced persistently;

(3) Targets experiencing physical-psychological damage;

(4) Targets labeling themselves as psychologically abused in the workplace;

(5) Targets with less power and having difficulty defending themselves.

Workplace bullying is an escalating process in the course of which the person who is targeted ends up in an inferior position and becomes the victim of systematic negative social acts by others. Itis evident, therefore, that a conflict cannot necessarily be labelled as workplace bullying if two people of approximately equal power are in non destructive conflict (Rayner \& Keashly, 2005, p. 273).

\section{Objectives of the Study}

The study intended to:

(1) Establish teachers' experiences of workplace bullying; 
(2) Establish sources of such workplace bullying;

(3) Establish the impact of workplace bullying on the health of teachers in secondary and high school in the Maseru district in Lesotho.

\section{Methodology}

The study adopted a qualitative research design and specificallya phenomenological design. According to McLeod (1995, p. 89), De Vos, Strydom, Fouché, and Delport (2005, p. 270), and Bryman (1988, p. 8), a qualitative study is relevant for gaining in depth insight into the experiences.

\section{Sampling for the Study}

The population for this study comprised of the high school and secondary teachers in the Maseru district in Lesotho.

Non probabilistic purposive sampling was used to select the sample for the study. This was found to be appropriate because only the participants who had personally experienced workplace bullying had to participate in this study.

The sample for the study comprised of 21 teachers, consisting of sixteen females and five males who had personally experienced bullying in their in workplace.

\section{Criteria for Inclusion in the Study}

In order to participate in the study the following criteria for inclusion was utilized:

(1) $\mathrm{He} / \mathrm{she}$ had to be a teacher by profession and be employed as a teacher at the time of research;

(2) He/she had to be teaching in the secondary or high school in the Maseru district in Lesotho;

(3) $\mathrm{He} /$ she should have identified himself/herself as having had unpleasant experiences in the workplace;

(4) $\mathrm{He} / \mathrm{she}$ should have expressed willingness to be interviewed by the researcher.

\section{Data Collection}

Data for this study was collected through semi structured phenomenological individual interviews. The participants were interviewed about their experiences, source and the impact that workplace bullying had on their health.

Anonymity and confidentiality agreement was presented and explained to the participants. The researcher and the individual participants read it together and both the researcher and the participants signed it as a binding agreement to both parties that the researcher shall only utilize the information gathered for research purposes alone and also that such information shall remain anonymous. Permission was sought from them to tape record the interviews for purposes of research and all the participants agreed.

The interviews were transcribed word for word in the Sesotho language. Then the same interviews were back translated to English by a language specialist. The researcher then requested two other language specialists to check the translation quality and appropriateness of five of the translated transcripts a procedure expounded by Phafoli (2006). These translations were found to be appropriate and therefore the researcher proceeded with data analysis.

\section{Results}

In the presentation of data analysis, it is important to note that while there were 21 participants, the aggregated experiences are more than 21 because the participants experienced more than one case of workplace 
bullying.

The interviews yielded an enormous amount of data and the results are summarised henceforth.

\section{The Experiences and Sources of Workplace Bullying}

The analysis of the interview data revealed that the experiences of workplace bullying against the respondents emanated from the five sources, being the management, the colleagues, subordinates, students and parents. It emerged that most experiences emanated from the management of the school.

Negative acts emanating from the management. In the context of this study the management of the school refers to the headmaster/headmistress, school board and heads of departments. The following acts of workplace bullying emanated from the school management. They are presented as reported by the participants below.

(1) Structural violence committed against teachers: Workplace bullying in the form of structurally related acts was reported by the participants. This refers to those negative acts that are intrinsic to workplaces and are built into the practices and policies. Most of the participants mentioned this as a serious concern for them. It transpired from the interviews that these acts are something they cannot sort out themselves as one of the participants stated that:

One newly employed teacher refused to teach one class because she was overloaded, the principal kept her on temporary grant and remarked as follows: Do you think a thing like you should be given a permanent grant?

(2) Being overworked and overloaded: Being overworked is a state in which person is forced to work beyond his or her capacity as a person and a professional as evidenced from some of the statements from the participants:

Participants mentioned being overworked at their workplaces and the following examples are evidence to this.

I work like a slave, I have simply too many classes to teach and I also have to carry some of the work home even on weekends.

There seems to be no limit to what one is expected to do around here teaching, marking, supervising manual work, extra murals etc..

(3) Experiencing verbal and physical aggression: Verbal aggression refers to unfair criticisms through yelling and shouting and even insulting. This was reported as rife by the participants. This took various forms including insults hurled at the participants. On the other hand, physical aggression manifests in the form of physical harm directed at the victim. The following verbatim quotes from the participants are providing some of the evidence to that:

I was once physically dragged before the class that I had refused to teach because of the way I was asked to do it. The principal brought me before the students and told them this: here she is and if she does not teach you, tell me, I will deal with her.

(4) Not being given support: The participants pointed to lack of support from the management. Lack of support is observed when those responsible fail to provide assistance in various forms, to enable an employee to carry out his duties efficiently. This was deduced from the following excerpts:

One day in a meeting, we were told by the principal that we should not attend to our extended family matters... because I am staying with a sickly nephew and the principal knew this. I was shocked by this insensitivity and lack of 
support.

I attended leadership skills course and just he wished he just took me off the course and placed somebody else... any way he had made it clear that I could learn all I want from the course but he would never allow me to use those skill in HIS school.

(5) Being undermined and coerced to engage in certain actions: Undermining in the workplace can occur at both professional and person levels. It refers to situations where a person is made to feel useless. On the other hand, coercion occurs when a person uses some form of power to get the person to do what he or she wants (Kiesker \& Marchant, 1999, pp. 63-64). The participants felt that they were being undermined and coerced at work and the following are some of the statements to that effect:

I worked in a church school was told that I had a temporary employment contract with the school and was asked to resign... this was not true, I had a permanent contract. An argument started and I was told that I have no respect for church authorities and was made to feel like I was committing a sin.

He decided on her own that the subject I teach will no longer be taught at the school. I spent months idling, I decided to resign and get a job elsewhere.

(6) Gossip and lies being spread: This involves talking about the person behind their back also saying things that are not true about them. It emerged from the interviews that gossiping about staff members by the management was a problem. This involved management gossiping about staff members with colleagues, students, parents and others. The following are some of the experiences that were stated by the participants:

I was shocked to learn that the new incoming principal knew everything about me and refused to offer me an accommodation at the school saying she had been reliably informed that I stay with me in laws and I should just continue staying there.

One day the principal lied saying that the students in one class had said I miss classes. I went to ask the same students and discovered it was not true.

(7) Being shown cynical behaviour and attitude: Some participants reported the cynical behaviour and attitude of the management towards them. This is observed when a person treats others suspiciously overlooking their good intentions and reading it as individual self enhancement (Andersen \& Bateman, 1997, p. 450). The following are some of the experiences articulated by the participants:

After I had suggested some improvements on peer evaluation teachers liked my idea, she developed a bad attitude and said that I act as if I am the principal at this school and act like I know too much.

$\mathrm{He}$ is always uncomfortable that if people further their studies and acquire higher qualifications they will undermine him.

(8) Lack of transparency on issues of concern: Participants reported that lack of transparency and withholding the necessary information was a problem for them. This is one of the features of workplace bullying expounded in the literature.

The participants felt that it made it difficult for them to plan their work and to also execute their duties appropriately. The following are some of the statements by the participants:

The headmistress hides information from us.For instance the reading of the financial statement was kept a secret and only the friends of the management were told so that they could give her support in the parents' meeting.

One day teachers were not told that therefore classes will end early imagine.

(9) Being and victimised: Victimization is making somebody suffer because you do not like them (Aquino 
\& Bradfield, 2000). Some respondents mentioned victimization acts in the hands of the management as it emerged from following statements:

I have been charged with defamation of character for reporting the principal to the board for abuse of power and maltreatment of us as teachers. I am scared.

Because of her hatred for me I am no longer allowed to attend training workshops offered by the MOE. I was also relieved of my duties in various committees in the school.

(10) Observing favouritism towards other staff members: Favouritism entails preferential treatment afforded some people that one likes and not others in the same setting. The respondents pointed out that favouritism towards other staff members by the management was a problem for them. The following are some of the statements from some of the participants:

Favouritism is rife here. For instance if I attend workshops and travel with the teacher that she likes she will give him taxi fare and she will not give me. So I no longer attend these workshops.

My salary was withheld for six months because the principal wanted me to resign wanting to employ her own favourite teacher in my post.

(11) Being isolated and given silent treatment: Some participants expressed that isolation and silent treatment they experienced from the management was of great concern for them. This involved acts of discrimination where a person is treated as an outsider and is not included in conversation or activities taking place in the school. This was evidenced from some of the verbatim statements:

She did not even greet me when he met me outside her office. Sometimes I think he takes me like one of the students.

Do you know how it feels like when someone treats you like you do not exist?

When there is a death in my family the management will act like there is nothing unlike for other teachers. I sometimes feel so alone here.

(12) Use of divide and rule: The policy of divide and rule is used by the management and the participants mentioned it in the following excerpts:

She uses divide and rule policy and if any new teacher's loyalty towards her is not clearly observed then such a teacher will suffer.

The division of the staff by the headmistress has led to open conflicts among teachers.

Negative acts emanating from the colleagues of equal status. Some of the participants experienced workplace bullying from the colleagues of equal status.

Several participants mentioned that colleagues are a source of their problems. These ranged from personal derogation to lack of acceptance as evidenced in the following direct excerpts.

(1) Exposed to personal derogation and disrespect: This refers to the negative acts that are aimed at hurting the person and attacking their credibility at personal level. Personal derogation was experienced by some of the colleagues. These included a range of acts as expressed in the following examples:

Some colleagues would remind me all the time that it was my turn to go to class... and would pass remarks like, why do they have to treat this poor child like this?

Colleagues make nasty comments about my weight.

My colleagues failed to treat me with respect, just calling me by first name despite the fact that I am married. Culturally this is unacceptable.

(2) Being isolated: Participants reported feeling lonely and in isolated in the workplace. This was deduced 
from the following quotes:

The situation got so bad that I no longer went to the staffroom I decided to stay in the department's office alone.

Teachers in this school could not accept me as one of their own, I became a loner.

(3) Having one's professionalism attacked: Participants expressed that some of the actions by colleagues were direct attacks on their professionalism. This involved acts that cast doubt on the victim's sense of professionalism. A concern was raised about this problem by some participants. The following examples attest to this:

As a new teacher I suggested that we should use spatula to measure salt in the home economics class, the colleague said salt is salt whether you use a spatula or not. She would refuse to buy stuff needed for teaching some topics... I would teach some topics to the students and she will go that class and teach them the same thing again. Just because I am her former student she cannot accept that I am professional like her and I happen to know the recent developments in the subject area.

Some colleagues would go to my students and ask them what they think of my teaching.

(4) Older staff sabotages staff relations: Some participants felt that older staff members were destroying the relationships among the staff members. The following statements provide some evidence to this.

... Later on I learned that older staff member had sought an employment for her child, before I was appointed and when I got the job she was angry... when I came she influenced other staff against me.

Being the youngest staff member they would send me around to get them water and to even make tea for them.

(5) Not being accepted: Lack of acceptance by colleagues was experienced by some participants as observed from the following excerpts. The victim feels like as outsider among his or her colleagues The following are some of the experiences that the participants related:

She had problems accepting that I am a teacher like her and I have recently qualified and therefore I am bringing new ideas to the subject.

Who are you to reprimand students? Were common from this colleague.

Negative acts emanating from subordinates. A few participants experienced workplace bullying from the subordinates in their specific school. They expressed that their subordinates act irresponsibly on purpose. They find this behaviour objectionable. The category workplace bullying acts emanating from the subordinates have emerged as follows:

Irresponsible teacher behaviour: This shows when people fail to perform their duties as expected, instead acting in an unacceptable manner. Some participants mentioned that irresponsible teacher behaviour was a problem for them. For example:

Teachers absent themselves from work without any valid reasons.

When mistakes related to their work are pointed out they get offended and start saying that I have favourite teachers.

Negative acts emanating from the students. Some other negative behaviour was observed from students which some teachers felt was disturbing for them.

Students behaving badly: Students' unacceptable behaviour disturbed some of the participants as shown in the following examples:

Some of these students here are old enough to be at university and they have no respect for us because they are adults already and they feel we cannot tell them anything. 
They come late in the morning and do not do homework...

\section{The Impact of Workplace Bullying on the Health of Teachers Subjected to Workplace Bullying}

The participants disclosed that their negative experiences in the workplace did have traumatic impact on their health. The effects have been divided into five categories which have been generated from the direct verbatim quotes by the participants. The categories are:

(1) Biological health effects;

(2) Psychological health effects;

(3) Spiritual effects;

(4) Social (ecological) effects;

(5) Metaphysical effects.

Biological health effects. Physical health effects refer to the impact that negative experiences have in the body of the victims. These effects present themselves in biological symptoms experienced by the participants. The physical health effects mentioned by the participants varied from serious to extremely serious. The main category "physical health effects" is evidenced from the following statements from some of the participants:

(1) Getting stress headaches: The participants mentioned experiencing headaches as a result of their experiences. Severity of these experiences is expressed in some of the participants' direct verbatim statements.

I would sit and stare into space with this severe headache... it's something that I cannot emphasize enough...

I have developed chronic headaches... my health is messed up and I find it disgusting that the person responsible does not care to change her behaviour.

I went to the Doctor because I had this terrible throbbing pain on the side of my head, he said it tension... that day I thought my head was going to explode.

It felt like I had a bus running through my head ...

(2) Developing high blood pressure: Some of the participants mentioned that they had high blood pressure problems as a result of their experiences. Some of the examples are quoted below:

I had high blood pressure for the first time.

My blood pressure was fluctuating. On some days it would be so high that I just stayed at home.

(3) Developing heart problems: Some participants mentioned experiencing serious heart problems as a result of their negative experiences in the workplace. They expressed their experiences as follows:

Since this... I have a severe pain on the side of my heart... I had to undergo a heart test where they check how your heart works etc.... they said it was not good. I am still so young now with this... no. My Doctor was concerned I told him that I have work problems.

I have serious heart problems... sometimes I feel like I am going to die... it makes me feel so.... so bitter... does anyone have a right to treat people like dirt?

(4) Had eating problems: The participants experienced eating problems. These include losing appetite or overeating. The following are examples of the participants' experiences:

I started overeating, I was eating every thirty minutes... I put on so much weight it was scary.

I was so stressed I could not eat and I lost weight, I was skin and bones... that are what stress did to me. I went through hell.

(5) Getting ulcers: Some participants developed ulcers resulting from their negative circumstances in the 
workplace.

I had a very bad heartburn and severe stomach pains and I was diagnosed with ulcers.

I always got pains after eating, and it was ulcers as the doctors told me.

(6) Losing of hair: Some participants lost hair due the stress they experienced, for instance the following were some of their statements on this issue:

I never believed such can happen...my hair started falling out and I developed bald Patches... I got more frustrated. Suffered hair loss... I lost confidence... I almost resigned.

(7) Experiencing body pains: Other participants had body pains as they experienced negative acts in their workplace. This is stated as follows:

My left arm was once put in Plaster of Paris because it was so severely painful yet it had no fracture or sprain of any kind. Doctors in the country could not figure out what the problem was, after some tests and $\mathrm{x}$ rays came back negative. I had to go to South Africa and I was diagnosed with severe stress....

On some days I would bath and dress for work and on my way there I would feel so sick with no specific ailment and I would just go to the doctor.

Psychological health effects. These refer to the negative effects that present in mental symptoms on the victim. Many participants mentioned that as result of their traumatic experiences they developed serious psychological symptoms. These ranged from demoralization to symptoms that translated to paranoia.

(1) Lack of motivation and demoralized: As a result of their experiences the participants felt demoralized and unmotivated. They stated that they lost interest in their jobs and related activities For example some participants stated the following:

I do not have motivation to do anything ... not even preparing for the lessons as I used to.

I got demoralized; there was no point of trying to do any good.

(2) Feeling depressed: This is the state where a person's mood is disturbed characterised by hopelessness, pervasive, absorbing and chronic feelings of loss of control (Riskind, 1997, as cited in Blasé \& Blasé 2003, p. 405).

The participants got depressed as a result of their unpleasant experiences and the severity of their experiences is evident in how they describe their symptoms in these statements.

I got very sick, I was always tired, and I became depressed. I was hospitalised as a result of this.

I have depression, stress medication including food supplements do not help me anymore. I had to go for acupuncture and that made it better. Whenever I get a call to the office I get very upset wondering what I am wanted for.

(3) Being aggressive: Aggression is one of the symptoms experienced by the participants due to their experiences.

This is deduced from the symptoms they describe in these statements:

I get very aggressive sometimes saying things I should not have said.

I honestly found it difficult to concentrate. When people do such things they get to you... even if you are strong.

I was prepared to fight physically.

(4) Feeling anxious: Blasé and Blasé (2003, p. 405) define anxiety as a kind of mobilization response to a future threat that may be developing or coming and that, one hopes can be avoided. The participants 
experienced some anxiety as expressed in the following statements:

I found it difficult to relax.

I always had my heart pounding because I was anxious all the time and I could feel my health going down.

(5) Having sleep problems: Sleep problems refer to a dramatic change in the sleep pattern, with the person either having problems falling asleep or staying awake. The participants mentioned experiencing sleep problems as a result of their experiences. They either sleep too little or too much for example they articulated it as follows:

I could not sleep due to a lot of worrying about what happens at work.

Sometimes I would just sleep for a long time find it so difficult to wake up...and would actually feel like sleeping more.

(6) Feeling paranoid: This is a pervasive and unwarranted tendency to interpret the actions of others as deliberately demeaning and threatening (Andreasen \& Black, 1991, p. 338). As a result of their experiences, some participants expressed health problems that amount to paranoia. This is expressed as follows:

I could not trust people at work; I always felt everyone was out to destroy me.

Whenever a colleague says something positive about me I always felt that it a bluff. This was a result of my eroded self-esteem.

Spiritual health (ecological) health effects. The participants developed symptoms related to their spiritual domain as result of their experiences.

The effects on the spiritual health have been expressed by the participants as demonstrated in the following direct quotations:

\section{Finding it difficult to stay focused when praying}

Working here is hell in its totality. I do not know what to pray about and for anymore.

\section{Questioning the presence of God in bad experiences}

Does God really allow these kinds of things to happen to his own people?

\section{Questioning what constitutes fairness}

I wonder if I know what goodness of people means anymore.

Social health (ecological) effects. The social effects present as those effects of negative experiences that have an impact on ones social life.

The social effects of negative experiences in the workplace were expressed by the participants as shown in these examples:

(1) Mood affecting interpersonal: This refers to the state where a person's moods swing from happiness to despondency (Andreasen \& Black, 1991:191) and this is how it was reported in this statement by one of the participants.

I would just get to work and did not feel like talking to anyone except, just to go to class, teach and be on my own. I sometimes felt so scared because I did not like even the students I taught.

(2) Feeling lonely and disconnected: The participants felt lonely and disconnected emotionally and physically from other people around them. This was expressed by the participants as seen in the following quotes: 
I was all by myself, confused trying to figure out what I did wrong.

I felt so lonely and wished that I could go far away from this place.

(3) Metaphysical effects: Several participants mentioned the effects of workplace bullying that are explicable in the metaphysical context.

Several participants mentioned the effects of workplace bullying that are explicable in the metaphysical context. The following subcategories with direct quotes attest to this:

(a) Disillusionment with the goodness of the world and its people: One participant stated that:

I thought people could be good in this world but now I do not know what to believe anymore.

(b) Developing a deep dislike for church schools and church, authorities: The following excerpt expresses what the participant felt:

After what she did to me I questioned my respect for the... church and its authorities. The church I was brought up in, with its authorities.

\section{Summary, Conclusions, and Recommendations}

Data from phenomenological interviews with victims of workplace bullying reveal teachers indeed experience various forms of workplace bullying in the schools where they work. These findings corroborate the findings from the research literature in terms of what constitutes workplace bullying experienced in the workplace.

These acts emanate from various sources such as management of schools to a large extent, colleagues to some extent and also from subordinates in cases of individuals who were in the management. Only two individuals mentioned acts that specifically relate to students and none were mentioned from Ministry of Education, parents, or community.

The health effects of these experiences as expressed by the participants were very serious. These included psychological health effects such as paranoia and depression. Some of the participants experienced physical ailments such as severe headaches and heart problems. There were metaphysical and spiritual effects as well. Social effects which are basically socially related included mood changes affecting interpersonal relation and loneliness and being violent towards others.

\section{General Recommendations}

There is need for teacher support through programmes that are aimed at empowering them and taking taking care of their needs particularly related to the impact of workplace bullying. This includes a provision of counselling and other psychological service as need arises.

The management of schools needs to work with staff members to establish a clear vision and mission and to plan their activities and allocation of duties in school so that all teachers feel equally responsible for what goes on in their workplace.

Schools should encourage more involvement of the parents and the community in the activities es of the school and to also provide information on the teaching and learning in the schools in their respective communities.

Holistic health promotion as a field of study could be made compulsory as part of the teacher training programmes at tertiary level in the country. 
Resident workplace health promotion specialist can be employed in the Ministry of Education to assist in the development of a national policy on holistic health promotion which would be infused in the human resource management department and enforced in all the ministries.

Free counselling services could be provided for individuals who are already damaged by their experiences of workplace bullying in the workplace.

Legal machineries that include grievance procedures could also be put in place in order to address issues of human rights abuses in the form of workplace bullying in the workplace.

\section{References}

American Psychiatric Association. (2000). Diagnostic and statistical manual of mental disorders (4th ed.). Washington, D.C.: American Psychiatric Association.

Andersen, L. M., \& Bateman, T. S. (1997). Cynicism in the workplace: Some causes and effects. Journal of Organisational Behaviour, 18, 449-469.

Andreasen, N. C., \& Black, D. W. (1991). Introductory text book of psychiatry (p. 565). London: American Psychiatric Press.

Aquino, K., \& Bradfield, M. (2000). Perceived victimization in the workplace: The role of situational factors and victim characteristics. Organization Science, 11(5), 525-537. Retrieved 30 January, 2007, from http://www.teachersupport.info/-22k

Balducci, C., Fraccaroli, F., \& Schaufeli, W. B. (2011). Workplace bullying and its relation with work characteristics, personality, and post-traumatic stress symptoms: an integrated model. Anxiety, Stress \& Coping, 24(5), 499-513.

Blasé, J., \& Blasé, J. (2003). The phenomenology of principal mistreatment: Teachers' perspectives. Journal of Educational Administration, 14(4), 367-422.

Bryman, A. (1988). Quantity and quality in social research. London: Routledge.

Bryman, A. (2001). Social research methods. New York: Oxford University Press.

Bryman, A. (2006). Mixed methods (Vol. 2). London: Sage.

De Vos, A. S., Strydom, H., Fouché, G. B., \& Delport, L. S. L. (2005). Research at grassroots for the social sciences and human service professions (3rd ed.). Pretoria: Van Schaik.

Einarsen, S. (1999). The nature and causes of bullying at work. International Journal of Manpower, 20(1/2), 16-27.

Einarsen, S., Raknes, B. I., \& Matthiesen, S. M. (1994). Bullying and harassment at work and their relationships to work environment quality: An exploratory study. European Work and Organizational Psychologist, 4, 381-401.

Einarsen, S., Hoel, H., Zapf, D., \& Cooper, C. (Eds.). (2010). Bullying and harassment in the workplace: Developments in theory, research, and practice. Crc Press.

Einarsen, S., Hoel, H., Zapf, D., \& Cooper, C. L. (2003). Bullying and emotional abuse in the workplace: International perspectives. London: Taylor \& Francis.

Einarsen, S., Matthiesen, S. B., \& Mikkelsen, E. G.(1999). Does time heal all wounds? Long term health effects of exposure to bullying at work. Bergen: University of Bergen. Retrieved 15 May, 2009, from http://www.pistes.uqam.ca/v7n3/pdf/v7n3a1en.pdf

Einarsen, S., Matthiesen, S., \& Skogstad, A. (1998). Bullying at work: Findings in public and private organizations. Journal of Occupational Health Safety, 14(6), 563-568.

Einarsen, S., Raknes, B. I., \& Matthiesen, S. M. (1994). Bullying and harassment at work and their relationships to work environment quality: An exploratory study. European Work and Organizational Psychologist, 4, 381-401.

Gilioli, R., \& Fingerht, M. A. (2003). Protecting workers' health (Series no 4). Geneva: WHO. Retrieved October 7, 2008, http://www.who.int/entity/occupational_health/publications/ harassment/en/index.html-19k

Harrington, S., Warren, S., \& Rayner, C. (2013). Human Resource Management practitioners' responses to workplace bullying: Cycles of symbolic violence. Organization, 1350508413516175.

Hoel, H., Sheehan, M. J., Cooper, C. L., \& Einarsen, S. (2011). Organisational effects of workplace bullying. Bullying and Harassment in the Workplace: Developments in Theory, Research, and Practice, 129-148.

Jackson, M., \& Ashley, D. (2005). Physical \& workplace bullying in Jamaica's health sector. Pan American Journal of Public Health, 18(2), 114-121.

Kieseker, R., \& Marchant, T. (1999). Workplace bullying in Australia: A review of current conceptualizations and existing research. Australian Journal of Management and Organisational Behaviour, 2(5), 61-75. 
Kirk, W., \& Walter, G. (2001). Teacher support group serve to minimize teacher burnout: Principles for organizing. Education, 2(2), 147-150.

Law, R., Dollard, M. F., Tuckey, M. R., \& Dormann, C. (2011). Psychosocial safety climate as a lead indicator of workplace bullying and harassment, job resources, psychological health and employee engagement. Accident Analysis \& Prevention, 43(5), 1782-1793.

Lewis, D. (1999). Workplace bullying: Interim findings of a study in further education in Wales. International Journal of Manpower, 20(1/2), 106-118.

Lewis, S. E., \& Orford, J. (2005). Women's experiences of workplace bullying: Changes in social relationships. Journal of Community \& Applied Psychology, 15, 29-47.

Leymann, H., \& Gustafsson, A. (1996). Mobbing at work and the development of post traumatic stress disorders. European Journal of Work and Organizational Psychology, 5(2), 251-275.

Mathisen, G. E., Einarsen, S., \& Mykletun, R. (2011). The relationship between supervisor personality, supervisors' perceived stress and workplace bullying. Journal of Business Ethics, 99(4), 637-651.

McLeod, J. (1995). Doing counselling research. Thousand Oaks, Calif.: Sage.

Namie, G. D., \& Namie, R. (2000). The bully at work: What you can do to stop the hurt \& reclaim your dignity on the job. Naperville, Ill.: Source Books.

Notelaers, G., Einarsen, S., De Witte, H., \& Vermunt, J. K. (2006). Measuring exposure to bullying at work: The validity and advantages of the latent cluster approach. Work and Stress, 20(4), 288-301.

Omari, M. (2003). Towards dignity \& respect: An exploration of antecedents \& consequences of bullying behavior in the workplace (Research report). Retrieved July 5, 2012, from http://www.jcipp. curtin.edu.au/local/docs/discussion/2005/1.03 Maryam\%20Omari_\%20Bullying.pdf

Phafoli, S. H. (2006). Variables influencing delay in antenatal clinic attendance among teenagers in Lesotho (Doctoral dissertation, Pretoria: University of Limpopo (Medunsa Campus)).

Randall, P. (2001). Bullying in adulthood: Assessing the bullies and their victims. New York: Brunner Routledge.

Rasku, A., \& Kinnunen, U. (2003). Job conditions \& wellness among Finish upper secondary school teachers. Psychology \& Health, 18(4), 441-456.

Rayner, C., \& Keashly, L. (2005). Bullying at work: A perspective from Britain and North America. In S. Fox, \& P. Spector (Eds.), Counterproductive work behaviors (pp. 271-296). Washington, D.C.: American Psychological Association.

Rayner, C., Sheehan, M., \& Barker, B. (1999). Theoretical approaches to the study of the bullying at work. International Journal of Manpower, 20(1-2). Retrieved May 20, 2010, from http://www.worktrauma.org/research/research_index.htm - 49k

Sheehan, M., Barker, M., \& Mccarthy, P. (2004). Analysing metaphors used by victims of workplace bullying. International Journal of Management and Decision Making, 5(1), 21-34.

Taris, T., \& Kompier, M. (2003). Challenges of longitudinal designs in occupational health psychology. Scandinavian Journal of Work Environment and Health, 29, 14.

Tehrani, N. (2001). Building a culture of respect: Managing bullying at work. London: Taylor \& Francis. 